\title{
Thermal Sensation and Comfort during Exposure to Local Airflow to Face or Legs
}

\author{
Kazuaki Yamashita ${ }^{1)}$, Juntaro Matsuo ${ }^{2)}$, Yutaka Tochihara ${ }^{1)}$, Youichiro Kondo ${ }^{3)}$, \\ Shizuka Takayama ${ }^{3)}$ and Hiroki Nagayama ${ }^{3)}$ \\ 1) Faculty of Design, Kyushu University \\ 2) Department of Ergonomics, Kyushu Institute of Design \\ 3) Nissan Motor Co., Ltd.
}

\begin{abstract}
The present study examined the contribution of local airflow temperature to thermal sensation and comfort in humans. Eight healthy male students were exposed to local airflow to their faces (summer condition) or legs (winter condition) for 30 minutes. Local airflow temperature (Tf) was maintained at $18^{\circ} \mathrm{C}$ to $36^{\circ} \mathrm{C}$, and ambient temperature (Ta) was maintained at $17.4^{\circ} \mathrm{C}$ to $31.4^{\circ} \mathrm{C}$. Each subject was exposed to 16 conditions chosen from the combination of $\mathrm{Tf}$ and $\mathrm{Ta}$. Based on the results of multiple regression analysis, the standardized partial regression coefficient of $\mathrm{Tf}$ and $\mathrm{Ta}$ were determined to be 0.93 and 0.13 in the summer condition, and 0.71 and 0.36 in the winter condition at the end of the exposure. Also, thermal comfort was observed to depend closely on the interrelation between $\mathrm{Tf}$ and Ta. The present data suggested that local airflow temperature is an important thermal factor regarding thermal sensation and comfort. J Physiol Anthropol Appl Human Sci 24(1): 61-66, 2005 http://www.jstage.jst.go.jp/browse/jpa
\end{abstract}

Keywords: thermal sensation, thermal comfort, local airflow, automobiles

\section{Background}

The major factors influencing thermal comfort in an automobile passenger compartment are ambient temperature, relative humidity, solar radiation, and so on. Some researchers have demonstrated that seat temperature also contributes to the passenger's thermal comfort (Brooks and Parsons, 1999; Yamashita et al., 2002). Although an automobiles' air conditioning system controls primarily ambient temperature, reliance on the air conditioner would be costly for controlling an automobile's entire interior thermal condition in regards to energy. Since an air conditioning system supplies temperatureregulated air to an automobile cabin via small vents, the automobile's passengers frequently receive local airflow.
Therefore, the local airflow should also be considered as an important factor in thermal comfort. Previous research has demonstrated that local airflow could affect subject's thermal sensation and comfort (Hagino and Hara, 1992; Taniguchi et al., 1992; Kato et al., 2001; Armada-da-Silva et al., 2004). These previous studies, however, did not discuss in detail whether local airflow temperature affected thermal sensation and comfort. Although it is clear that local airflow temperature could affect thermal sensation and comfort in our daily life, few studies have focused on the contribution of local airflow temperature to thermal sensation and comfort experimentally. Therefore, the present study examined the effects of local airflow temperature on thermal sensation and comfort under various ambient temperatures in terms of subjective data in human tests, and investigated heat loss in a thermal manikin test.

\section{Methods}

\section{Human test}

The subjects were eight healthy male students (age; $23.4 \pm 1.5$, BMI; 20.7 \pm 1.8 ). The purpose and the procedure of this study were explained to them in detail, and each of them signed a consent form. A climatic chamber and an airflow machine, in which temperature, relative humidity, and airflow velocity could be controlled independently, were prepared for the experiments. Local airflow was supplied to the subjects via a duct. Summer and winter conditions were designed in the present study. The details of each seasonal condition are shown in Table 1. The conditions of ambient temperature (Ta) were designed by the predicted mean value (PMV) (Fanger, 1970) based on the clothing in each seasonal condition. The conditions of local airflow temperature (Tf) were $18^{\circ} \mathrm{C}, 24^{\circ} \mathrm{C}$, $30^{\circ} \mathrm{c}$ and $36^{\circ} \mathrm{C}$ in common in each seasonal condition. The relative humidity in the chamber and the local airflow were maintained at $50 \%$ in every condition. Local airflow velocity was set at $1.0 \mathrm{~m} / \mathrm{sec}$ in every condition. The subjects's faces 
Table 1 Details of the experimental conditions

\begin{tabular}{|c|c|c|}
\hline & Summer & Winter \\
\hline Clothing (clo) & 0.44 & 0.84 \\
\hline Exposed site to the airflow & face & legs \\
\hline Diameter of duct $(\mathrm{cm})$ & 23.5 & 30.0 \\
\hline Local airflow temp. $\left({ }^{\circ} \mathrm{C}\right)$ & 24.0 & 30.0 \\
\hline $\begin{array}{l}\text { Ambient temp. }\left({ }^{\circ} \mathrm{C}\right) \\
\text { (PMV) }\end{array}$ & $\begin{array}{lllll}23.9 & 26.4 & 28.9 & 31.4 \\
(-1) & (0) & (+1) & (+2)\end{array}$ & $\begin{array}{cccc}17.5 & 20.7 & 24.1 & 27.4 \\
(-2) & (-1) & (0) & (+1)\end{array}$ \\
\hline
\end{tabular}

were exposed to the local airflow in the summer condition and their legs were exposed to the flow in the winter condition. The subjects participated in 16 conditions chosen from the combination of Ta and $\mathrm{Tf}$.

Measurements included skin temperature at 16 sites (forehead, chest, back, abdomen, upper arms, forearms, hands, thighs, legs, and feet), local thermal sensation (face, chest, back, upper arms, forearms, hands, thighs, legs, and feet), overall thermal sensation, and thermal comfort. Skin temperature was obtained by means of a thermistor, and was recorded in a portable data logger (LT-8A, Gram) every second. Thermal sensation and comfort were expressed according to scales ranging from -3 (too cold) to +3 (too hot) regarding thermal sensation, and from -1 (uncomfortable) to +1 (comfortable) regarding thermal comfort. First, the subjects rested for 30 minutes in a climate chamber. Thereafter, they were exposed to the local airflow, and registered their thermal sensation and comfort every 2 minutes.

\section{Thermal manikin test}

We also conducted a thermal manikin test in order to estimate heat loss in each body site. A thermal manikin, in which body segments were divided into 16 parts, was exposed to 26 experimental conditions. The clothing conditions were the same as those in the human test. Data regarding heat loss was recorded to a personal computer every minute. Representative data was obtained when the stability of heat loss was identified during the exposure.

\section{Results}

Figure 1 shows skin temperature, thermal sensation in the subjects, and heat loss in each body segment of a manikin at the end of the exposure under a thermoneutral ambient temperature in the summer and the winter conditions. Skin temperature and thermal sensation showed a stepwise change following $\mathrm{Tf}$ at the exposed sites and the adjacent sites in each seasonal condition (Figs. 1(a), (b)). In the manikin test, heat loss in the winter condition was affected by $\mathrm{Tf}$ in most segments, whereas Tf caused the change in heat loss locally on the face and chest in the summer condition (Fig. 1(c)).
Figure 2 shows the relationship between Tf and the change in skin temperature during the exposure, overall thermal sensation, and thermal comfort at the end of the exposure in each seasonal condition. Skin temperature at the sites to be exposed to the local airflow varied exclusively following $\mathrm{Tf}$ (Fig. 2(a)) in both seasonal conditions. In addition, a similar tendency was observed in overall thermal sensation (Fig. 2(b)). Although skin temperature and overall thermal sensation showed a linear relationship to $\mathrm{Tf}$, thermal comfort showed a complex relationship to $\mathrm{Tf}$ in each seasonal condition. In the summer condition, thermal comfort peaked when $\mathrm{Tf}$ was $24^{\circ} \mathrm{C}$ under a $31.4^{\circ} \mathrm{C} \mathrm{Ta}$, and did also when $\mathrm{Tf}$ was $30^{\circ} \mathrm{C}$ under $26.4^{\circ} \mathrm{C}$ and a $28.9^{\circ} \mathrm{C}$ Ta. However, thermal comfort showed no peaks under $23.9^{\circ} \mathrm{C}$ in Ta (Fig. 2(c)). In the winter condition, thermal comfort showed a peak under Ta's of $24.1^{\circ} \mathrm{C}$ and $27.4^{\circ} \mathrm{C}$, and no peaks in thermal comfort were seen when $\mathrm{Ta}$ was $17.4^{\circ} \mathrm{C}$ and $20.7^{\circ} \mathrm{C}$, respectively.

In order to estimate the contribution of $\mathrm{Tf}$ and $\mathrm{Ta}$ to overall thermal sensation and comfort, a multiple regression analysis was performed. The analysis revealed that both $\mathrm{Tf}$ and $\mathrm{Ta}$ showed significant relationships to overall thermal sensation in each seasonal condition except thermal comfort (the adjusted $\mathrm{R}$ square was less than 0.1 ). Figure 3 shows the time course of the standardized partial regression coefficient (SPRC) of $\mathrm{Tf}$ and $\mathrm{Ta}$ to overall thermal sensation during exposure. The SPRC of Tf increased from the start of the exposure, and was saturated at 4 minutes of exposure under both seasonal conditions. At the start of the exposure, the SPRC of the Ta in the winter condition was approximately equal to that of $\mathrm{Tf}$. Thereafter, the SPRC of the Ta in the winter condition decreased slightly and maintained a lower level during the exposure. On the other hand, the Ta in the summer condition showed considerably lower SPRC compared with that of the Tf, and showed little change though the exposure. At the end of the exposure, the SPRCs of Tf and Ta were 0.93 and 0.13 in the summer condition, and 0.71 and 0.36 in the winter condition, respectively.

\section{Discussion}

The present study aimed to examine the effect of local airflow temperature on thermal sensation and comfort. The local airflow temperature caused a stepwise change in skin temperature and local thermal sensation at the exposed sites and the adjacent sites (Figs. 1(a), (b)). In the summer condition, the local airflow was supplied locally to the forehead and the chest, since heat loss was changed by Tf only at these sites in the manikin test (Fig. 1(c)). Skin temperature, however, showed a marked change following $\mathrm{Tf}$ at the sites in which the local airflow was not supplied directly in the summer condition. These results may be induced by secondary physiological responses resulting in the facial thermal stimulus. Nagai et al. (1996) reported that facial heating caused an increase in the peripheral skin temperature and tympanic temperature in a cool environment. Also, Kato et al. 


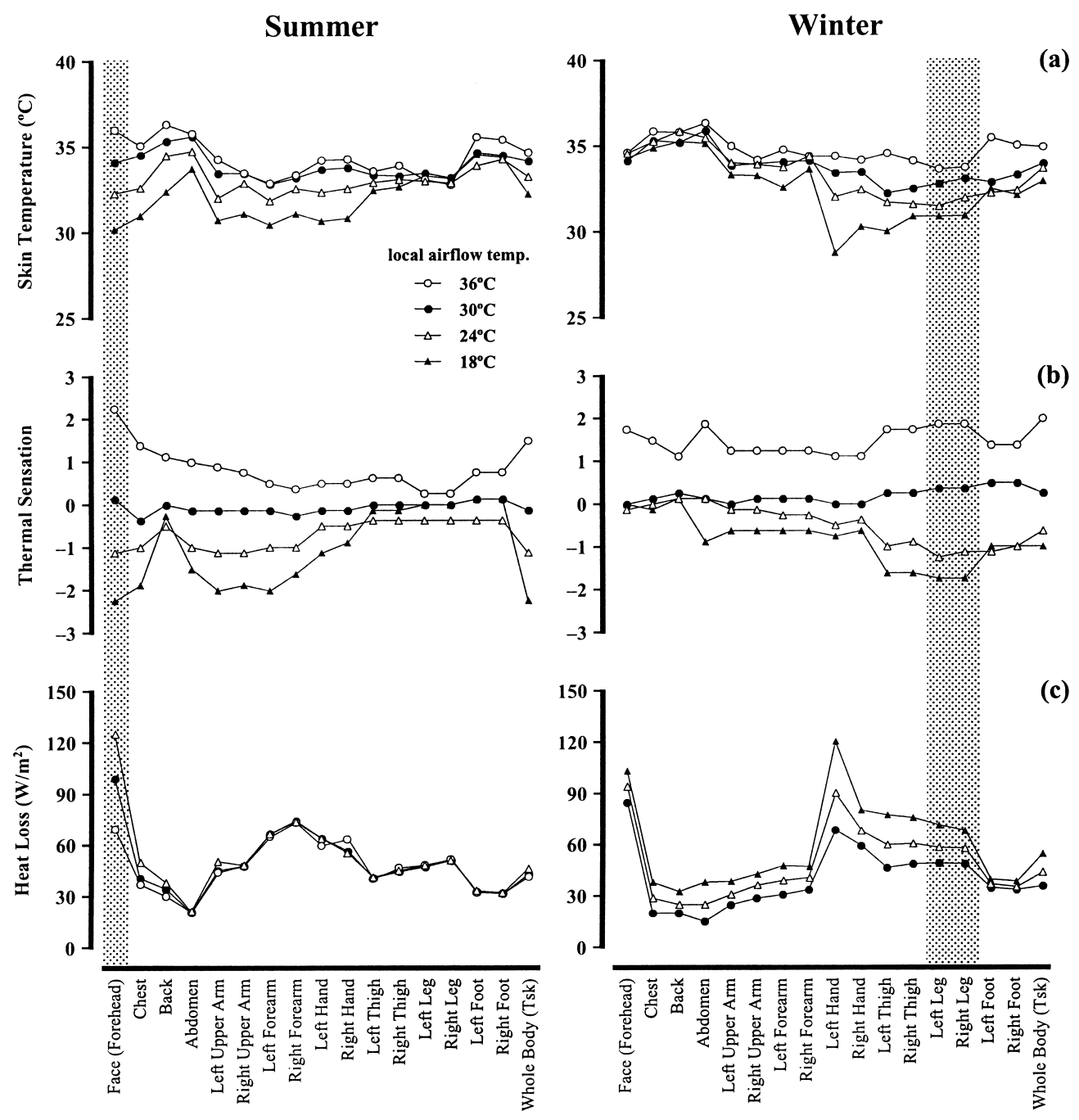

Fig. 1 Skin temperature (a) and thermal sensation (b) in the subjects, and heat loss in a manikin (c) at each body segment. Values in the human test are means. The shaded area indicates the exposure sites to the local airflow in each seasonal condition.

(2001) demonstrated that facial fanning caused a decrease in tympanic and esophageal temperature during hyperthermia. Thus, a facial thermal stimulus could cause a change in core temperature and in subsequent physiological responses. Therefore, it could be considered that the local airflow to the face could also induce a change in peripheral skin temperature in the summer condition. In the winter condition, the thermal manikin test demonstrated that the local airflow to the legs brought about a change in heat loss in the systemic body segments. A possible reason for these results is the diffusion of local airflow toward various sites of the body and the subsequent change in the peripheral ambient temperature around the manikin. Thus, the systemic change in skin temperature and thermal sensation by $\mathrm{Tf}$ in the winter condition would be induced by the direct effect of the local airflow temperature even at the sites which were not exposed to the local airflow.

In both seasonal conditions, $\mathrm{Tf}$ contributed more prominently to overall thermal sensation than $\operatorname{did} \mathrm{Ta}$ throughout the exposure (Figs. 2(b), 3). In particular, overall thermal sensation depended exclusively on $\mathrm{Tf}$ in the summer condition. This result suggests that a facial thermal stimulus could have a predominant effect on overall thermal sensation, and also supports the suggestion described in previous research (Taniguchi et al., 1992; Hagino and Hara, 1992; Boutcher et al., 1995; Nagai et al., 1996; Kato et al., 2001; Armada-daSilva et al., 2004; Zhang et al., 2004). Although Tf also showed a higher contribution to overall thermal sensation in the winter condition, this result would be induced by a change in the thermal state of the whole body by the local airflow, as shown in Fig. 1(c). In addition, the local airflow to the legs seems to have little effect on overall thermal sensation just after exposure (Fig. 3). Therefore, the local airflow supplied to the face rather than to the legs would have more effect on overall thermal sensation.

While overall thermal sensation showed a linear relationship to $\mathrm{Tf}$, thermal comfort did not show unidirectional reactivity to Tf (Fig. 2(c)). As shown in Fig. 2(b), overall thermal sensation 

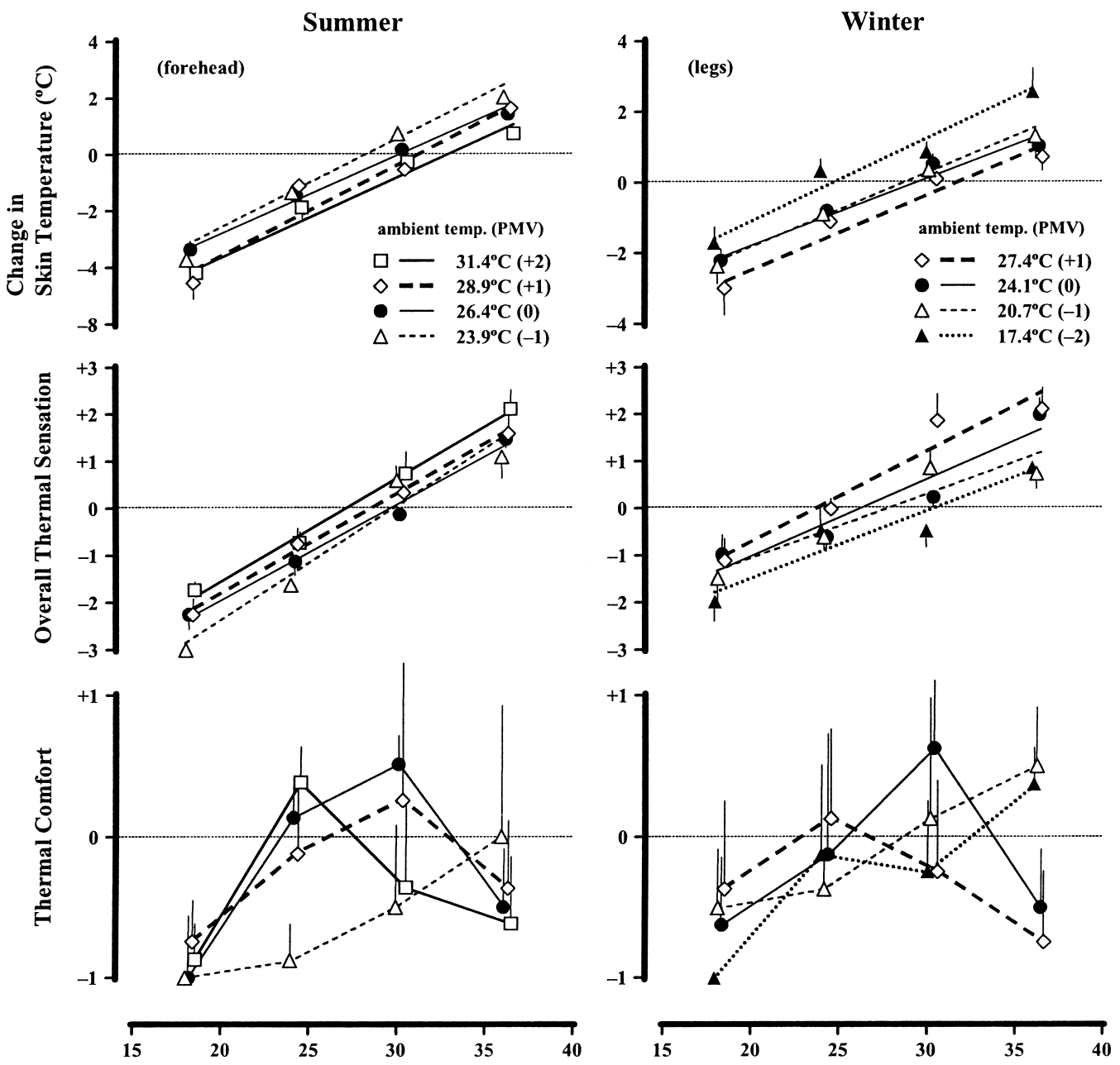

Local Airflow Temperature $\left({ }^{\circ} \mathrm{C}\right)$

Fig. 2 The relationship between local airflow temperature (Tf) and change in skin temperature at the forehead (right) and at the legs (left) (a), overall thermal sensation (b) and comfort (c) in the summer and the winter conditions. Values are means and \pm S.E.

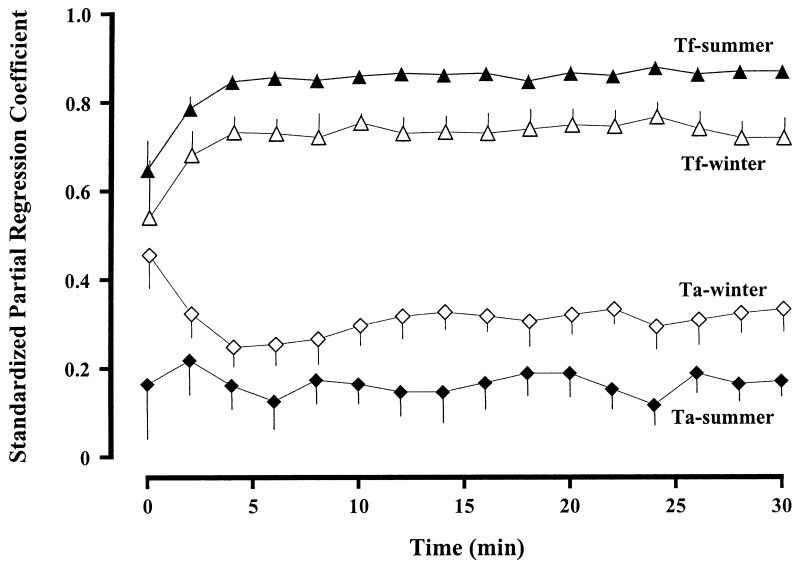

Fig. 3 Standardized partial regression coefficients (SPRC) of local airflow temperature (Tf) and ambient temperature (Ta) to overall thermal sensation in the summer and the winter conditions. Values are means and \pm S.E. was voted as "neutral" at a $\mathrm{Tf}$ of $30^{\circ} \mathrm{C}$ at Ta's of $26.4^{\circ} \mathrm{C}$ and $28.9^{\circ} \mathrm{C}$ in the summer condition and at a Tf of $24^{\circ} \mathrm{C}$ at Ta's of $30^{\circ} \mathrm{C}$ under $27.4^{\circ} \mathrm{C}$ and $24.1^{\circ} \mathrm{C}$ in the winter condition. Under these conditions, thermal comfort showed its highest value compared with other conditions of Ta as shown in Fig. 2(c). However, thermal comfort also showed a peak when $\mathrm{Tf}$ and $\mathrm{Ta}$ were $24^{\circ} \mathrm{C}$ and $31.4^{\circ} \mathrm{C}$, respectively, in the summer condition, though thermal sensation was simultaneously registered as "slightly cool". In addition, thermal comfort showed a progressive increase following Tf under several conditions. Zhang et al. (2004) suggested that maximum comfort shifted towards cold or warm based on the thermal state of the body. Similarly, comfortable local airflow temperature could also shift based on ambient temperature in the present study. A cool or a warm airflow would be preferred in an extremely hot or cold environment. Accordingly, it could be considered that thermal comfort might depend on the interrelation between local airflow temperature and ambient temperature. This indication would also suggest that temperature-regulated local 
airflow could possibly bring about a comfortable feeling even in uncomfortable thermal environments. Thus, attention should be paid to the interrelation between local airflow temperature and ambient temperature in attempts to achieve thermal comfort in an automobile.

There may be some difficulty in applying the present data directly to actual automobile thermal environments, since the present experimental situation was far from an actual one in terms of the wide exposure area and the long exposure time to local airflow. However, it is significant that the present data demonstrated that overall thermal sensation and comfort is closely dependent on local airflow temperature. Although the relative humidity and velocity of the local airflow was fixed in every experimental condition, these thermal factors would also affect thermal sensation and comfort. In particular, the local airflow in which relative humidity was set at a higher level induced severe discomfort for the subjects in preliminary experiments. The effects of these thermal factors of local airflow on thermal sensation and comfort should be examined in the future.

In conclusion, the present data demonstrated that local airflow temperature made a significant contribution to overall thermal sensation and comfort. These results suggest that local airflow temperature should be considered as an important factor in the design of an automobile's thermal environment.

Acknowledgements This study was supported in part by Grant-in-Aid for the 21st Century COE Program.

\section{References}

Armada-da-Silva PAS, Woods J, Jones DA (2004) The effect of passive heating and face cooling on perceived exertion during exercise in the heat. Eur J Appl Physiol 91: 563-571

Attia M, Engel P (1981) Thermal alliesthesial response in man is independent of skin location stimulated. Physiol Behav 27: 439-444

Boutcher SH, Maw GJ, Taylor NAS (1995) Forehead skin temperature and thermal sensation during exercise in cool and thermoneutral environments. Aviat Space Environ Med 66: 1058-1062

Brooks JE, Parsons KC (1999) An ergonomics investigation into human thermal comfort using an automobile seat heated with encapsulated carbonized fabric (ECF). Ergonomics 42: 661-673

Fanger PO (1970) Thermal Comfort. Danish Technical Press, Copenhagen

Hagino M, Hara J (1992) Development of a method for predicting comfortable airflow in the passenger compartment. SAE Technical Paper Ser 922131: 1-10

Holmér I, Nilsson H, Bohm M, Noren O (1995) Thermal aspects of vehicle comfort. J Physiol Anthrolpol Appl Human Sci 14: 159-165

Huizenga C, Zhang H, Arens E (2001) A model of human physiology and comfort for assessing complex thermal environments. Build Environ 36: 691-699

Ishida O, Tajima O, Matsuno $\mathrm{T}$, Yasui $\mathrm{K}$, Taniguchi $\mathrm{Y}$, Matsunaga K, Yano T (2001) Thermal comfortable environment in automobile cabin. Reito 76: 571-577 [In Jalanese]

Kato M, Sugenoya J, Matsumoto T, Nishiyama T, Nishimura $\mathrm{N}$, Inukai Y, Okagawa T, Yonezawa H (2001) The effects of facial fanning on thermal comfort sensation during hyperthermia. Pflügers Arch 443: 175-179

Katsuura T, Tabuchi R, Iwanaga K, Harada H, Kikuchi Y (1998) Estimation of thermal sensation during varied air tempreature conditions. J Physiol Anthrolpol Appl Hum Sci 17: 73-78

Matsunaga K (2003) Research of the comfortable vehicle interios of a room. Isuzu Gihou 109: 37-44 [In Japanese]

Matsunaga K, Sudo F, Tanabe S, Madsen TL (1993) Evaluation and measurement of thermal comfort in the vehicles with a new thermal manikin. SAE Tecnical Paper Ser 931958: 35-43

Matsuo J, Yamashita K, Tochihara Y, Kondo Y, Takayama S, Nagayama H (2004) Effect of thermal stimulus by local airflow on thermal comfort. J Physiol Anthrolpol Appl Hum Sci 23: 59

Nagai Y, Yamasaki K, Iizuka S, Nakamura K (1996) Physiological and psychological effects of head heating during rest and work. J Physiol Anthrolpol Appl Hum Sci 15: $227-237$

Nunneley SA, Maldonado RJ (1983) Head and/or torso cooling during simulated cockpit heat stress. Aviat Space Environ Med 54: 496-499

Nunneley SA, Reader DC, Maldonado RJ (1982) Headtemperature effects on physiology, comfort, and performance during hyperthermia. Aviat Space Environ Med 53: $623-628$

Roberts KB, Roberts EC (1976) The automobile and heat stress. Pediatrics 58: 101-104

Rohles FH, Wallis SB (1979) Comfort criteria for air conditioned automotive vehicles. SAE Technical Paper Ser 790122: 440-449

Rugh JP, Farrington RB, Bharathan D, Vlahinos A, Burke R, Huizenga C, Zhang H (2004) Predicting human thermal comfort in transient nonuniform thermal environment. Eur $\mathrm{J}$ Appl Physiol 92: 721-727

Samuel SN, Kolka MA, Cadarette BS, Montain SJ, Sawka MN (2003) Efficacy of intermittent, regional microclimate cooling. J Appl Physiol 94: 1841-1848

Tanaka M, Kobayashi Y, Kawagoe K (1982) The influence of unequal air current distribution on the human body part. 2 thermal sensation and comfort vote by exposing to the fast air movement only for the lower part of the body. Int $\mathrm{J}$ Biometeorol 26: 356

Taniguchi Y, Aoki H, Fujikake K, Tanaka H, Kitada M (1992) Study on car air conditioning system controlled by car occupants' skin temperatures-part 1: Research on a method of quantitative evaluation of car occupants' thermal 
sensations by skin temperatures SAE Paper Ser 920169: 13-19

Yamashita K, Kuroda T, Tochihara Y, Shibukawa T, Kondo Y, Nagayama H (2002) evaluation of summertime thermal comfort in automobiles. Environmental Ergonomics $\mathrm{X}$ : 789-792

Wyon DP, Wyon I, Norin F (1996) Effects of moderate heat stress on driver vigilance in a moving vehicle. Ergonomics 39: $61-75$

Zhang H, Huizenga C, Wang D (2004) Thermal sensation and comfort in transient non-uniform thermal environments. Eur J Appl Physiol 92: 728-733
Received: September 6, 2004

Accepted: October 18, 2004

Correspondence to: Kazuaki Yamashita, Faculty of Design, Kyushu University, 4-9-1 Shiobaru, Minami-ku, Fukuoka 815-8540, Japan

Phone: +81-92-553-4522

Fax: +81-92-553-4302

e-mail: yam@design.kyushu-u.ac.jp 